\title{
CORPOS, HETERONORMATIVIDADE E PERFORMANCES HÍBRIDAS
}

\author{
BODIES, HETERONORMATIVITY AND HYBRID PERFORMANCES
}

\author{
Ricardo Pimentel Méllo \\ Universidade Federal do Ceará, Fortaleza, Brasil
}

\section{RESUMO}

Maneiras de viver, muitas vezes, são naturalizadas como se houvesse uma forma predeterminada de corpo feminino ou masculino, nos remetendo vivência de nossos corpos como inertes, em oposição à alma imortal e ativa. Os corpos são qualificados como materialidades biológicas, sendo experimentados como provas de nossa sexualidade e da existência de gêneros e aqueles que não se acomodam a essas normalizações são tratados como "abjetos". O movimento feminista se opôs as pressupostas diferenças biológicas entre homens e mulheres utilizando o conceito de gênero, mas o sexo permaneceu como categoria básica e o corpo como matéria inerte. Como não sucumbir a perspectivas binárias e dicotômicas? Como fazer de nossas vidas experimentações que ousem transbordar as normalizações histórico-culturais? A partir de estudos queer propõem-se corpos como vibráteis, estranhos, formados e dobrados em redes, uma instigação de resistência à ação de isolamento do que se considera abjeto como consequência da biopolítica.

Palavras-chave: estudos queer; performatividade; corpos vibráteis; relações de gênero.

\begin{abstract}
Ways of life often are naturalized as if there was a predetermined shape of the female and male body. The bodies are classified as a biological materiality, which is experienced as evidence of the existence of our sexuality and gender. Thus, bodies that do not accommodate to these norms are treated as abjects. To counteract this biological assumption, the feminist movement began to use the concept of gender in order to strip of the supposedly biological differences between male and female. However, the sexual organ is still the basic category for differentiation and the body is still understood as an inert materialization. How not to succumb to binary perspectives? How to live a life that dares to overflow the historical and cultural commonalities? Taking the queer studies' perspectives, it is put forward an idea of bodies as vibratile, strange, freakish devices made and molded in social webs; this is a proposal of biopolitical resistance to the isolation imposed on the abjects.
\end{abstract}

Keywords: queer studies; performativity; vibratile bodies; gender relations.

\section{A constituição do olhar clínico e o imperativo médico: a naturalização dos sexos}

O corpo, especialmente sob influência da cultura judaico-cristã, muitas vezes designa o inerte, o que se opõe a alma, esta sim viva, perene imortal, ativa. Como afirma Fontes (2006, s.p.) "a dicotomia entre animado e inanimado ... permitiu a palavra corpus passar a indicar os objetos materiais - isto é, visíveis". Dessa forma, corpo tem uma materialidade sensível que, por essa característica, passa a ser definido como natural e biológico, como se fosse autodefinido e independente de práticas culturais, ou seja, como se os corpos sempre fossem os mesmos em função de uma composição material essencial.

$\mathrm{Na}$ Idade Média, via-se uma diferenciação dos corpos mais do que da sexualidade, esta explicada pelo calor vital, como mostram os estudos de Thomas
Laqueur (2001). Só havia como modelo único o corpo masculino, sem a padronização de uma determinada terminologia para a genitália feminina. A mulher não tinha um órgão sexual específico. Seu órgão sexual apenas não havia se desenvolvido adequadamente e por isso tinha se enrustido, se voltado para dentro. Galeno foi o grande representante dessa forma de atuar sobre o corpo, chamada de "modelo de sexo único". A mulher era um homem invertido, por isso imperfeita e inferior. Assim, como no Gênesis, a mulher origina-se do homem, este sim fisicamente perfeito.

O cristianismo herda essa concepção de corpo e a arrasta para a sua mais intensa disjunção com a vida. Afinal o corpo é menor diante da alma. O corpo, "a carne", pode nos inviabilizar a redenção eterna. Deve ser escondido, evitado. E não é à toa que as "representações" de Deus são masculinas. 
Por outro lado, os movimentos de libertação que têm visibilidade especialmente a partir da metade do século passado (especialmente movimento feminista e LGBT), buscam inverter essa tradição de esconder corpos deixando-os a mostra de modo extremo. São os corpos nus, seminus de passarelas, de revistas de sites ditos pornográficos. Busca-se a perfeição do corpo e menos a perfeição da alma. Nas artes os corpos são expostos, como por exemplo, na dança contemporânea em oposição à dança clássica.

De todos os modos, persistem os usos do corpo como uma massa moldável. A massa sendo natural e o ser humano podendo aperfeiçoar o natural com práticas de musculação, cirurgias plásticas, alimentação, etc.

A sexualidade dos corpos permanece na modernidade como sendo natural, predefinida por Deus ou pela natureza. Temos corpos masculinos e femininos com fins de reprodução. O que a natureza não consegue é deixá-los tão perfeitos e assim o ser humano dá uma mãozinha com um siliconezinho ou uma toxinazinha. Assim, existimos em corpos biologicamente definidos pela natureza como sendo masculinos e femininos; corpos considerados naturalmente sexuados e a pressuposta prova material disso é a diferença nas genitálias. Ninguém olha a bunda "igual". O que pode ser igual é de pronto rejeitado como identificador de gênero. Esse tipo de conhecimento sobre os corpos humanos é abordado por Donna Haraway (2009) como prática política que opera materializando e naturalizando maneiras de viver.

Constituído o imperativo do olhar bioclínico ou biomédico, a diferença advinda desse olhar generaliza-se para outras partes do corpo. Com a ajuda importante dos estudos anatômicos esboça-se essa diferença generalizada a partir do século XVIII, afirmando a natureza das finalidades dos corpos femininos à maternagem $\mathrm{e}$ dos masculinos à valentia, à guerra:

um dos aspectos mais significativos dessa revolução nos discursos médicos do século XVIII, foi a reavaliação dos órgãos reprodutores femininos que, de imperfeitos e pouco evoluídos, passaram a ser vistos como perfeitos e adequados à maternagem. Mas, além disso, deu-se uma mudança fundamental: o sexo passou a ser pensado como permeando todo o corpo humano, isto é, como algo que não estaria circunscrito apenas aos órgãos genitais. De acordo com esta perspectiva, a diferença entre os sexos marcaria toda a extensão do corpo e fora da genitália haveria muitas outras diferenças significativas. ... O modelo antigo... de calor vital sai definitivamente de cena, dando lugar à idéia de uma diversidade biológica. (Nunes, 2000, p. 39)

As diferenças sexuais serão milimetricamente traçadas. Não resta quase nada nos corpos inertes que seja igual para os dois sexos. Cria-se a perspectiva binária que vai além dos corpos chegando até as almas.
Se os corpos são binariamente heterossexuais as almas também. Há uma essência masculina e outra feminina. Em outras palavras, há uma alma feminina e uma alma masculina, ou ainda, modos de ser essencialmente masculinos ou femininos.

O olhar médico-clínico não se atém só aos estudos anatômicos e vai, no século XIX, com a utilização do microscópio nas pesquisas médicas, dar início à patologia moderna, inaugurando a chamada "Fase Celular", em que se desenvolvem estudos de Citologia e Histologia, área reservada hoje à Histopatologia. Esse olhar acha-se ainda mais verdadeiro, pois supõe ir além do olho humano, como se os aparelhos cada vez mais minuciosos, dispensassem esse olhar e enxergassem por si sós. As diferenças sexuais são fixadas, mas ainda considerando-se o corpo inerte, só que agora em dimensões microscópicas. Tanto que se há dúvida quanto ao sexo pelo olhar da genitália, apela-se ao código genético e à dosagem hormonal. Com a Biologia Molecular, na interface entre a Bioquímica e a Genética, os exames clínicos definidores do sexo ampliam o olhar anatômico na montagem do corpo sexuado. Por outro lado, Clara Pinheiro (2006) defende que o saber médico está sofrendo um processo de mudança, a partir da hegemonia da biologia molecular:

Desse modo, a atividade monótona, cotidiana, do olhar médico sobre a singularidade do corpo doente, é substituída pela leitura de uma configuração genética codificada, que, podemos dizer, não tem nada de pessoal. Com isso, a relação médico-paciente deixa de ser o cerne da prática médica. Com sua estrutura de genes codificada, é possível - este é o sonho de muitos geneticistas - que cada indivíduo possa ter seu genoma particular, que poderá vir transcrito num compact disc (Reid, 1992). Tal objeto deterá o segredo, se segredo houver, de cada individualidade, que, enfatizamos, não tem nada de singular e de pessoal. (Pinheiro, 2006, p.9)

Desde a antiguidade diversas transformações na concepção de práticas corporais vão sendo constituídas, até chegarmos aos modos de viver dos nossos dias (e noites!): um corpo diagnosticado.

Portanto, de práticas gregas de separação entre corpo e o espírito, à criação do sexo biológico separando homens e mulheres pela diferença anatômica e molecular, podemos compreender que todas essas concepções/práticas referiram-se especialmente a como os seres humanos governavam as suas vidas gerenciando seus corpos considerados inertes. Essa é a biopolítica descrita por Foucault, que busca retirar dos corpos a sua máxima eficácia:

eu entendia por isso a maneira como se procurou, desde o século XVIII, racionalizar os problemas postos à racionalidade governamental pelos fenômenos próprios de um conjunto de viventes constituídos em 
população: saúde, higiene, natalidade, longevidade, raças... (Foucault, 2008, p. 431)

Foucault argumenta que a partir do século XVIII se buscou racionalizar a prática governamental direcionando-a a um conjunto de viventes (população), problematizando-se, por exemplo, saúde, higiene, natalidade, longevidade, raça, trabalho etc., com o intuito de regular a população (Castro, 2009, p. 60).

Entendia-se o corpo como tendo uma existência anterior a qualquer de nossas experiências "nele" ou "dele". Então nesse sentido - por mais paradoxal que possa parecer - trata-se de uma relação em que o corpo é tido como inerte. Porém podemos argumentar que nem mesmo nas concepções que veem indícios no corpo que designam o que é ser homem ou mulher (por exemplo, pênis e vagina) teríamos um corpo inerte, uma vez que sempre se produz determinadas práticas corporais e modos de viver. Mas é preciso enfatizar que esse posicionamento coloca o corpo como inerte, uma vez que é ele que nos proporciona sinais naturais que ditam modos de ser (homem, mulher, deficiente, criança, velho etc.). Sendo assim os corpos não são abjetos, mas o uso deles sim; eles não são por si imundos ou desprezíveis, mas seu uso pode ser vil. Os corpos são seres viventes habitados por seres de direitos que precisam ser governados. Essa tecnologia de governo propõe problemas específicos a serem geridos.

Abjeto é o que causa repulsa, o que é desprezível. Judith Butler (2008) afirma que a matriz de relações de gêneros são fronteiras rígidas construídas em performances normativas fixadas por serem repetidas vezes divulgadas e demonstradas. Seres, corpos, que não se acomodam a essas normas, são tratados como abjetos. Como exemplo, temos a mulher cantada na música "Se acaso você chegasse" de Lupicínio Rodrigues e Felisberto Martins (gravada em 1939). Lupicínio havia "roubado" a namorada de outro compositor seu amigo, Heitor de Barros, e preferindo não "perder a amizade" decidiu contar-lhe tudo compondo a música. Heitor acabou "trocando o falso amor" pela "amizade verdadeira" de Lupicínio. Ou seja, a mulher, violou o que se pressupõe ser sua condição natural de passiva, tornando-se um corpo abjeto. Há inúmeras situações assim.

\section{Corpos sexuados e heterossexuais}

Criados os corpos inertemente sexuados, ou seja, corpos tatuados pela natureza que nos ditam como devemos habitá-los, sendo a tatuagem principal a que se encontra nas genitálias, temos consequências importantes: se existem diferenças e o corpo feminino é perfeito à maternagem (portanto ao privado) e o masculino é perfeito à guerra (portanto ao público), os corpos só devem se unir também de modo perfeitamente normal: um homem com uma mulher. A heterossexualidade é o modelo de normalidade. Fora desse modelo temos patologias: um corpo mal tatuado pela natureza ou um ser que deseja mudar a tatuagem natural. Vemos que não se trata de um preconceito exclusivamente religioso, mas uma afirmação científica.

Outras consequências: mulheres devem se restringir ao lar e os homens têm que ir à luta por emprego para sustentar suas famílias. Neste modelo bélico, quem vai à luta não pode ser então um corpo feminino. E quem está em casa na vida doméstica não pode ser um corpo masculino. Quando a heterossexualidade se torna uma normalidade, mais do que uma discussão entre a diferença dos sexos (genitália), temos essa distinção sendo utilizada para fundamentar as discussões feministas e de gênero. A noção de heterossexualidade, por fazer parte de um arranjamento biopolítico, avança sobre movimentos reivindicatórios. O imperativo biológico tenta se manter de alguma forma por meio de corpos inertemente sexuados, entenda-se "corpos biológicos" e heterossexuados.

\section{O movimento feminista e o conceito de gênero}

As mulheres desconfiam do lugar naturalmente subordinado que as ciências, as religiões, o Estado, as mídias, lhes reservaram e começaram a questionar a atribuição e assunção de uma natureza frágil. Ainda sem questionar a inércia de um corpo naturalmente sexuado: "O uso da palavra 'gênero', como já dissemos, tem uma história que é tributária de movimentos sociais de mulheres, feministas, gays e lésbicas. Sua trajetória acompanha as demandas por direitos civis, direitos humanos, enfim, por igualdade e respeito" (Pedro, 2005, p. 78).

Em especial nos anos 1980, o movimento feminista inicia o uso do conceito de gênero, com o intuito de desnaturalizar as pressupostas diferenças biológicas entre homens e mulheres. Assim, a categoria gênero é incorporada às pesquisas e textos acadêmicos, nas quais se veiculam temas como, por exemplo, violência doméstica, dupla jornada de trabalho, sexualidade, direitos reprodutivos e doenças sexualmente transmissíveis. Além de textos, o movimento também reúne a discussão de gênero em oficinas a fim de propiciar às mulheres espaço de discussão e questionamento sobre suas vidas. $\mathrm{O}$ objetivo era o de desnaturalizar a diferença entre homens e mulheres estes ainda tidos como categorias essencialmente universais.

No final da década de 1990, abre-se espaço para discussões sobre "masculinidades" utilizando gênero 
como categoria analítica. Nesse caso, se "reafirma a historicidade de relações de gênero, a sua importância como pressuposto estruturador da experiência e das relações, criticando posições essencialistas e relacionando o modo como se dá a percepção dos papéis de gênero com a dominação e o poder" (Monteiro, 1997, p. 1). A ênfase nos estudos sobre masculinidades é na produção e circulação de saberes e sentidos acerca do que é ser homem. Estudos sobre a paternidade, por exemplo, são apontados por Margareth Arilha, Sandra Ridente e Benedito Medrado (1998) como tendo se tornado um campo importante de ações e investigações. Vide a campanha "Dá Licença, eu sou pai!"’ proposta pela Rede de Homens pela Equidade de Gênero - RHEG $^{4}$, com o objetivo informar os homens sobre a prerrogativa da licença paternidade, incentivando sua participação no cuidado de filhos ou adoção. Ao mesmo tempo Benedito Medrado alerta para que a paternidade não se transforme em um mito a exemplo da maternidade (Medrado, 1998). Todos esses estudos estavam sob a égide do que começou a circular como "perspectiva relacional do gênero", ou seja, gênero não é um atributo inerente a uma natureza humana predeterminada advinda de uma organização biológica, seja uma identidade feminina ou masculina, mas gênero constitui-se como modelo cultural construído a partir de relações historicamente construídas.

Desse modo o movimento feminista avança no sentido de questionar qualquer tipo de essencialidade sexual marcada previamente nos corpos: o binarismo masculino versus feminino, a natural maternidade, o natural vigor masculino etc. Um dos posicionamentos que tem sido colocado em discussão é gênero como "performance". Judith Butler lançou esta maneira de abordar o tema, ou seja, o gênero é fruto de determinado modo como uma cultura organiza uma sociedade, não sendo reflexo de um sexo determinado biologicamente, mas este sendo o efeito da matriz de gênero:

Butler estaria tentando deslocar o feminismo do campo do humanismo, como prática política que pressupõe o sujeito como identidade fixa, para algo que deixe em aberto a questão da identidade, algo que não organize a pluralidade, mas a mantenha aberta... (Rodrigues, 2005, p. 179)

Para essa autora, gênero é uma prótese performática que materializa um corpo. Porém ainda permanece o sexo como categoria básica e o corpo como matéria inerte, naturalmente dimórfico. É como se a "espécie humana" tivesse dois diferentes tipos de indivíduos, homens e mulheres, que desempenham papéis ou apresentam performances, que podem ser entendidas como “estilos corporais" (Bento, 2006, p. 92). O gênero não é biológico, mas se expressa em um corpo pela repetição de um estilo que é suposto como sendo fundado na natureza da espécie (Butler, 2003). Assim, um ponto parece se perpetuar: a noção de performance pressupõe um corpo inerte. E com ajuda das ciências "psi" o tal corpo inerte é compreendido como depositário de uma identidade, (algumas vezes até mutante), ou como espaço de produção do "si", da subjetividade.

$\mathrm{O}$ que mudou em relação às práticas dos séculos XIX e primeira metade do século XX: o olhar desnaturante transformado em performances e, portanto, mudaram as formas de produção de si. O que permaneceu: um corpo usado para a performance, esta localizada nas relações construídas por homens e mulheres. O corpo ainda é inerte.

Vejamos como exemplo a citação que consta do Dicionário de Direitos Humanos da Procuradoria Geral da República do Ministério Público Federal:

Gênero é uma categoria relacional do feminino e do masculino. Considera as diferenças biológicas entre os sexos, reconhece a desigualdade, mas não admite como justificativa para a violência, para a exclusão e para a desigualdade de oportunidades no trabalho, na educação e na política. É um modo de pensar que viabiliza a mudança nas relações sociais e, por conseqüência, nas relações de poder. É um instrumento para entender as relações sociais e, particularmente, as relações sociais entre mulheres e homens. (Procuradoria Federal dos Direitos do Cidadão, 2009)

E agora uma citação de Scott:

uma rejeição do determinismo biológico implícito no uso de termos como "sexo" ou "diferença sexual". O termo gênero enfatizava igualmente o aspecto relacional das definições normativas da feminilidade. Aquelas que estavam preocupadas pelo fato de que a produção de estudos sobre mulheres de maneira demasiado estreita e separada utilizaram o termo "gênero" para introduzir uma noção relacional em nosso vocabulário analítico. Segundo esta visão, as mulheres e os homens eram definidos em termos recíprocos e não se poderia compreender qualquer um dos sexos por meio de um estudo inteiramente separado. (Scott, 1995, p. 72)

Aparentemente, retira-se o conteúdo biologicista da sexualidade, mas de algum modo, se mantém o que se pretende excluir: a base biológica que se configura num corpo inertemente sexuado. Daí a "identidade sexual", antes vista como normalmente heterossexual, é questionada, amplia-se para incluir homossexuais, lésbicas, travestis, transexuais, intersex etc. A perspectiva de gênero leva adiante a afirmativa de que, algumas vezes, o "sexo biológico e o psicológico não coincidem". Como se houvesse uma essencialização do "sexo psicológico" ou como se este antecedesse ou precedesse o "sexo biológico", nos mostrando de novo que a binaridade corpo-alma e a noção de corpo inerte, depositária antes de um sexo e agora de gênero, insistem e persistem nas nossas relações. 


\section{O movimento queer e os corpos vibráteis}

Como não sucumbir na dicotomia público-privado, objeto-sujeito, masculino-feminino, corpo-alma, subjetividade-objetividade, sexo-gênero? Como não utilizar corpos como se fossem matérias inertes? Compreendo que essas perguntas guiam de algum modo o questionamento à perspectiva de gênero relacional que ainda essencializa o corpo o biologicizando. Em outras palavras, a perspectiva de corpo sexuado implica uma concepção de corpo inerte.

Se com a perspectiva de gênero se afirma que não existe sexo anterior a cultura, alguns estudos ampliam a crítica e alegam que "não existe um corpo anterior a cultura: ao contrário ele é fabricado por tecnologias precisas" (Bento, 2006, p. 21). Não só o gênero pode ser uma categoria de análise, mas o corpo também. Podemos encontrar alguns trabalhos sendo feitos nesta perspectiva (Ver, por exemplo, Sant'Anna, 1995, 2001; Soares, 2006). Em outras palavras, a gestão política de gêneros também se aplica aos corpos. E aí podemos inclusive verificar a crítica a "performatividade de gênero", que ainda constitui corpos como se fossem roupas vestidas por gêneros, ou gêneros que transformam as roupas-corpos para uma performatividade do "eu" (no caso dos transexuais, por exemplo). Não há como buscar uma harmonia entre uma "identidade sexual" descolada do corpo. Aliás, não há harmonia porque o corpo humano não é inerte, mas foi sendo constituído, inventado, por isso é vibrátil (do latim, vibratus, índica ação do que é suscetível de vibrar: Cunha, 1986, p.820).

Nesse sentido, também podemos rever algumas posições de Butler. Quando Beatriz Preciado (2002, 2008), ao analisar as tecnologias de gênero, propõe a "contra-sexualidade" como prática de resistência à hegemonia binária e heteronormativa, chama a atenção para a sociedade ocidental constituída como "sociedade farmacopornográfica", ou seja, caracterizada pela gestão simultânea de modos de viver por meio de hormônios, cirurgias e meios audiovisuais. Esta gestão desenvolvida a partir da Segunda Guerra Mundial distinguiu corpos binariamente heteronormativos em bio e trans. Os bio são os que se identificam com o gênero que lhes foi tatuado desde o nascimento e os trans como os que buscam tecnologias para modificar o gênero tatuado. Nossas sociedades funcionam como laboratórios psicofarmacológicos que fabricam gêneros e corpos enfatizando supostas diferenças.

Ora, mas ambas as classificações de bio e trans, são consideradas por Preciado como tecnogêneros, fundamentalmente por serem sempre inventados por tecnologias que dobram o corpo ou o flexionam sobre alguma maneira de viver. Deste modo, gênero deixa de ser um conceito ou uma "performance", para se consti- tuir em uma política, ou melhor, biopolítica. Não são os atos em si que interessam por nos dizerem sobre alguma "performance", mas as políticas de gestão de governo que produzem gêneros. Isso nos leva a conclusão de que se não há por si gêneros, também não há por si "performances de gênero". Caso o conceito de "performativo" ou "performance" se apresentem como discursos/ práticas que operacionalizam os corpos, temos ainda resquícios de realismo materializados nos corpos. Em vez de corpos vibráteis temos corpos matéria onde se efetuam discursos/práticas.

A diferenciação de Preciado em relação às propostas de Butler, (ainda que aquela deva a esta créditos importantes de seu percurso de filósofa e militante feminista), é que o corpo farmacopornográfico não é dócil. É possível resistir às normalizações de sexo e gênero em operações de desnaturalização do gênero programado, tatuado, por meio, por exemplo, da experimentação hormonal. Não há limite para a manifestação contra-sexual do corpo (observo que não escrevi no corpo). Não há regiões que podem ser recortadas universalmente como masculinas ou femininas, ou como mais prazerosas que outras, e se são assim consideradas é porque estão afeitas a determinadas políticas que podem ser modificadas. Se o corpo tem alguma anatomia, não é "performativa", mas biopolítica. Se algum corpo é nominado, não é por causa de uma natureza que o faz crescer de uma determinada forma, ou por causa de uma "performance de gênero". Não podemos separar o corpo de uma forma de governo como se ele obedecesse a alguma classificação. Estas advêm de regras e práticas absolutamente arbitrárias, sem uma referencia a ser provada no corpo. Em entrevista Butler afirma:

eu acho que discursos, na verdade, habitam corpos. Eles se acomodam em corpos; os corpos na verdade carregam discursos como parte de seu próprio sangue. E ninguém pode sobreviver sem, de alguma forma, ser carregado pelo discurso. Então, não quero afirmar que haja uma construção discursiva de um lado e um corpo vivido de outro. (Prins \& Meijer, 2002, p.164)

Por mais que afirme não separar corpo vivido de corpo discursivo, ainda inicia sua frase acentuando que o corpo é habitado por discursos. E como temos "acesso" ao corpo? Por meio de discursos, ou dos "sentidos" evocados nos discursos? Será que agindo assim não estamos ainda no campo representacional de corpo que tanto criticamos?

Se pensarmos o corpo não como efeito de discursos ou invólucro de uma identidade seja lá qual for, mas como máquina (Deleuze, 1992), que se define no seu funcionar ou não funcionar, podemos entender a proposta de Preciado. Não é o motor especificamente em si que define o carro: se tiramos esse motor e o colocarmos em um ultraleve ele funciona de modo diferente e deixa 
de ser carro. Muda a política de seu uso. Então, como separar o motor, da política ou do gerenciamento de seu uso? Na perspectiva aqui adotada, seria impossível. $\mathrm{Na}$ concepção de máquina em Deleuze, podemos entender o corpo como uma composição, que se constitui sob ações e discursividades diversas: biologia, psicologia, física, religião etc. Ou seja, como uma máquina plural de elementos que se encadeiam e se enredam, proporcionando certos movimentos, certas direções.

Os corpos não contêm nenhum sexo e nenhuma performance definida, mas se constituem no modo como são vividos em uma potencialização política heterocentrada: medicalização, cirurgias, ornamentação, indústria pornográfica, tecnologias jurídicas e midiáticas, congressos científicos etc. Essas políticas mais que regular os corpos, os maquinizam. Corpo é gerenciamento biopolítico, gestão (calculada) sobre os fluxos da vida. Definiu-se que o corpo tem sexo e os usos diferenciados que se devem fazer dele. Ele, o corpo, é o próprio acontecimento no que ele se faz em fluxos: "O Império dos normais desde os anos 50 depende da produção e da circulação em grande velocidade dos fluxos de silicone, fluxos de hormônios, fluxo textual, fluxo das representações, fluxo das técnicas cirúrgicas, e, em definitivo, fluxo de gêneros" (Preciado, 2004, p. 2).

Não visto como efeito (resultado de algum ato), mas como feito (acontecimento, ação), o corpo se faz vida humana e nele se gerencia como, por que, com que finalidade a vida deve fluir para ser "autenticamente humana". No fluir da vida (das condições nas quais esta deve se efetivar) o corpo resulta como esquadrinhado em cada mínimo pedaço, que divididos terão funções e gerenciamentos específicos. O sexo passa a ter um lugar importante nesse gerenciamento, inclusive para produção do trabalho. Por exemplo: alguém tem de cuidar do corpo tornado homem que trabalha e produz e esse alguém é o corpo tornado feminino. Veja-se que o corpo não é reprimido (nem a sexualidade ou o sexo), como bem apontou Foucault, mas se faz na sua própria gerência. O que nos corpos se forma é a gerência deles, algumas persistentes e insistentes há séculos. $\mathrm{O}$ corpo se faz em múltiplas redes de força, que por isso nos permitem compreender que a estratégia de Foucault não é o indivíduo (que pode ser compreendido como os nós dessa rede), mas sobre as condições de possibilidades sobre os saberes e poderes que fazem essa rede. O indivíduo é formado na e pela rede materialmente, discursivamente: "o intuito primordial da sociedade normalizadora, mais do que reprimir a conduta do indivíduo, é influenciá-lo, conduzi-lo e incliná-lo, por meio de mecanismos dispositivos, no sentido de submeter determinada posição de corpos a certos acessos históricos de saberes/poderes" (Silveira \& Furlan, 2003, p. 182).
É importante frisar que Preciado (2008) critica o modo como Foucault desenvolveu seus estudos "sobre o corpo". Parece que antecede a essa discussão específica esclarecer o foco dos estudos de Foucault que dá margem para que surja esta crítica. Em função da concepção de poder como criador mais do que repressor, Foucault estudou os dispositivos que transversalizavam o corpo ao mesmo tempo em que lhe davam uma determinada disposição, como sendo o invólucro de um indivíduo. Ou seja, colocou à mostra o corpo da sociedade moderna que permaneceu como espaço onde a alma (se quisermos a psique, a identidade, a personalidade) se expressa. Foucault, bem sabemos, critica a posição de uma interioridade psicológica, ao mesmo tempo em que dá visibilidade a esse dispositivo psicológico na formação da vida humana. De todo modo, ele trata o corpo como superfície de inscrição de práticas e saberes. E isso é criticado por Preciado em função da sua prática de resistência onde usa o próprio corpo. Mas, podemos compreender isso como estratégias diferentes de análise, mais do que divergências:

Foucault se coloca, assim, em "Vigiar e Punir" (1975) e "História da Sexualidade" (1976), do lado de fora da experiência do corpo próprio, porque estava interessado, sobre tudo, na lógica do poder sobre o corpo ou no sistema de forças e saberes que o atravessam. (Silveira \& Furlan, 2003, p. 183)

Preciado faz de seu corpo a sua militância e crítica ao sistema de forças e saberes que se querem hegemônicos. Digamos que ela esteja em um segundo tempo, em relação a Foucault que usou a sua escrita como estratégia de resistência prioritariamente. Instrumentalizou quem teve acesso aos seus escritos para dele fazerem o que quiserem. E Preciado (2002, 2004, 2008) dobrou esses escritos sobre si, fazendo do seu próprio corpo força de resistência em uma experimentação micropolítica, dosando-se hormônio; fazendo-se nele e dele um manifesto contra-sexual. Por isso defendo que devêssemos compreender estas posturas não como divergentes, pois falam do corpo como centro da vida humana para possibilitar uma relação de cada indivíduo consigo mesmo - burilado assim em um olhar biomédico (órgãos, funções) e, ao mesmo tempo, jurídico-político (sujeito as normas, correções, punições tendo em vista a "qualidade de vida") — mas, ambas as posturas utilizando o corpo de modo estrategicamente diferente.

Atenho-me agora à discussão sobre os chamados transexuais e intersex por considerá-la fundamental, por possibilitar que se rompa com a estratégia de viver o corpo como circunscrito a uma determinada corporeidade natural (como nos estudos queer), e também por ser uma discussão fundamental para se compreender a 
exposição realizada até aqui. No primeiro caso, transexuais, há "troca de sexo" cirúrgica por se considerar que alguém tem uma "identidade" que não combina com sua genitália, ou seja, com seu corpo. Neste caso temos um corpo "sadio", salubre, higiênico, em uma "identidade" que adoece por não "se encaixar" nesse corpo. No segundo caso dos intersex, há o diagnóstico de uma "genitália ambígua". Não temos um corpo são e assim temos a "certeza" de uma patologia diagnosticada por médicos e psicólogos. Dentre os critérios que são utilizados para a decisão pelo ato cirúrgico, Paula Machado (2005) aponta os funcionais e estéticos:

Para o sexo feminino, os fatores mais levados em consideração, em ordem de importância, são: a capacidade reprodutiva e a possibilidade de reconstrução anatômica de uma vagina que possibilite mais tarde, para a mulher, relações sexuais prazerosas (o que é associado à preservação das enervações do clitóris) e que possa ser penetrada por um pênis. Para o sexo masculino, aparecem os seguintes fatores, também em ordem de importância: o tamanho e a capacidade erétil do pênis; a possibilidade de sentir prazer (o que é associado à ejaculação) e de penetrar adequadamente uma vagina; a capacidade reprodutiva; e a capacidade de urinar de pé.

A questão da funcionalidade do corpo está bastante imbricada com aquilo que se espera socialmente de homens e mulheres. Assim, se a capacidade reprodutiva desponta como elemento preponderante nas decisões de definição para o sexo feminino, o desempenho sexual (penetrativo, com pênis de tamanho e capacidade erétil considerados adequados) ocupa o mesmo papel para o sexo masculino. (Machado, 2005, p.274)

Seguindo na mesma linha, temos também a Labioplastia, para a medicina compreendida como cirurgia de correção nos pequenos lábios. Mas correção de que? De uma anomalia? Para alguns movimentos a tal correção é vista como uma mutilação na mesma linha das cirurgias de "correção" dos intersex:

é mutilação, é estragar o que já é perfeito. Que graça tem em se parecer tudo igual? Queremos xoxotas grandes, beiçudas, enrugadas, polpudas, e também com clitóris enormes, grossos e eretos, para que possamos admirá-las e chupá-las até vocês terem os mais intensos dos orgasmos e até nos saciarmos com seus néctares. Queremos que você olhe no espelho e admire-se, que brinque com sua volumosa e deliciosa buceta e jamais pense em mutilá-la em nome de uma indústria que não tem piedade e que não está nem um pouco preocupada em deixá-las mais bonitas, mas em faturar milhões. Não se deixe enganar! (Beauty Vulva) ${ }^{1}$

$\mathrm{Na}$ troca de "gênero", de sexo, há algo que prejudique a "comunidade"? Não. Nos dois casos, transexuais e intersex, há preceitos guiados por noção de sexo natural, biológico. Há uma ontologização dos seres humanos mantidos como homens ou mulheres.

Em relação aos transexuais deve-se pedir licença ao Estado, após um longo processo de avaliação diagnóstica. Se diagnosticado como alguém que tem realmente uma "identidade" que não combina com seu corpo, lhe é autorizado. No caso de intersex, geralmente crianças, também é o Estado que autoriza a alteração da genitália, também após diagnóstico médico, com acompanhamento psicológico da família.

E qual o crime de intersex? Nenhum. Quando do diagnóstico de "ambiguidade", a operação é um "direito" alimentado pelo Estado. A diferença é que se fará uma cirurgia "reparadora de uma deficiência". A "ambiguidade" na genitália impõe a cirurgia, feita sob a justificativa de proteger a criança de problemas de discriminação. Mas sabemos que não é bem assim, porque uma vez diagnosticado como ambíguo, o chamado hermafrodita/intersex, para sempre levará este estigma. A discriminação já antecede a cirurgia e não finda com ela.

Essa faceta jurídica que implica na autorização do Estado inclui uma importante discussão sobre a autonomia das pessoas que desejam realizar cirurgias trans e intersex. Como apontamos acima a legislação brasileira condiciona a cirurgia "à confirmação do diagnóstico psiquiátrico de transexualismo - transtorno de identidade de gênero ou sexual —, e ao acompanhamento psiquiátrico por dois anos para sua realização" (Ventura \& Schramm, 2009, p. 65). Esse diagnóstico deve ter o carimbo de "verdadeiro transexual". Como se as pessoas que desejam modificar a anatomia de seu corpo, nem sempre estejam certas de seu desejo e como se devêssemos ter essa certeza. Esta certeza deve impor ao "mutante" o dispositivo da confissão (assumir que é doente, que apresenta uma patologia e precisa da medicina para ser curado ou para pelo menos amenizar a sua dor). Mas, é o saber médico que sabe sobre o corpo dos humanos e o único a realizar o veredictum (verdadeiramente dito). Como concluem Ventura e Schramm (2009, p. 67): "só é possível o acesso aos recursos disponíveis com a tutela da Medicina e do Direito, e não como uma escolha livre do sujeito transexual, nem como resultado de um acordo entre as partes". A justificativa para a tutela do Estado não podia ser pior:

a intenção de beneficência e de proteção do paciente transexual, considerando as extensas e irreversíveis modificações corporais, e a natureza de sua doença - transtorno psíquico - que pode limitar sua capacidade de decidir sobre as intervenções adequadas a serem realizadas em seu corpo. (Ventura \& Schramm, 2009, p. 67)

Dessa forma, o "verdadeiro transexual" é incapaz por princípio. Porém, quando se trata de outras interven- 
ções cirúrgicas, como a alteração do nariz, da barriga etc., o Estado se mantém fora da discussão. Pode-se argumentar que se trata de intervenções "qualitativamente diferentes", porque se muda a personalidade, o caráter, a identidade do transexual. Outra justificativa risível, mas compreensível diante do biopoder ou controle das populações pelo Estado, é a de que este "cidadão" mutante teria duas identidades. Em síntese, a "portabilidade" de um pênis ou vagina origina a classificação das pessoas nas estatísticas e informações da sociedade como um todo. Caso contrário, teríamos de excluir as informação sobre "gênero" de inúmeros formulários que dão origem a avaliações estatísticas e admitir que o ser humano não se define a partir dele. Os/as brasileiros/as têm o "direito" de mudar o que quiserem no "seu" corpo, menos as genitálias. Não importa que, como no caso do "homem gato", façam-se cirurgias que nos deixem "irreconhecíveis", desde que a identidade de gênero que tem como suporte natural os órgãos genitais, não seja tocada. Se há uma genitália definida como masculina, por exemplo, qualquer dúvida de quem a porta sobre isso só pode ser doença da mente, na medida em que o corpo está normal. A consequência grave é:

a exclusão, no sistema oficial de saúde, do/a paciente que não preencha os critérios do diagnóstico para o acesso às modificações corporais. Isto implica que as pessoas excluídas busquem as modificações corporais (implante e aplicação de silicone, ingestão de hormônio e outros) no mercado clandestino ou as realizem elas mesmas, o que implica riscos e mesmo danos irreversíveis para sua saúde e integridade física. (Ventura \& Schramm, 2009, p. 88)

Como estabelecer uma diferença tão rígida entre público e privado? É um disparate a reivindicação de mudança de sexo em nome do privado, para que a criança não sofra em público. Ou é uma bobagem a cirurgia trans para que o adulto não sofra mais. Não será a cirurgia que fará um corte definitivo em preconceitos e biopoliticas. E o sofrimento advindo da operação? O corte, a cirurgia, a internação, os medicamentos "pra toda a vida"? Os olhares sobre aqueles corpos cirurgicamente modificados mudarão? Claro que não. Serão sempre olhares de dúvida expressos nas perguntas: "afinal que gênero te pertence? Qual é o teu verdadeiro sexo? Diga-me quem és?"

Para implantes de silicone em seios de alguém definido como feminino é bem diferente. É para "turbinar", um neologismo advindo do substantivo feminino "turbina". A que remete essa palavra? Remete a turbina de avião, a subir, alcançar céus, em outras palavras, se tornar uma deusa, vista, percebida, sobretudo desejada.

Colocar uma prótese em uma pessoa considerada hermafrodita é turbinar? E em um transexual? Não, é reparar. É tentar "consertar" o que a natureza não conseguiu. O "super-homem" ao identificar um estranho intervém para criar um corpo normal, mas coloca o intersex e trans nesta condição para toda a sua vida.

A prótese não é simplesmente um artefato, mas é o gerenciamento dos corpos.

Os corpos trans são "abjetos", ou seja, não importam (Butler, 2008; Prins \& Meijer, 2002). Como afirma Butler: "tais corpos não são inteligíveis (argumento epistemológico) e não têm uma existência legítima (argumento político ou normativo)" (citado por Prins \& Meijer, 2002, p.156). São abjetos porque, "não são consideradas "vidas' e cuja materialidade é entendida como "não importante"" (citado por Prins \& Meijer, 2002, p.161). Não são institucionalizados em códigos vivos de legitimidade, mas em códigos que os matam como patológicos e ilegais. Devem ser expulsos de nossos "chatôs", casebres, barracos, apartamentos, casas. E só podem entrar nas universidades se forem patologizados.

Diante de tudo isso, temos os estudos Queer como uma proposta de resistência a ação de isolamento do que se considera abjeto.

A própria sexualização dos corpos deriva de tais performances. No processo de reiteração das performances de gênero, algumas pessoas, fora da matriz heterossexual, passam a ser consideradas abjetas. A política queer consiste em perturbar os binarismos de gênero e brincar com as menções feitas sobre gênero espaço privilegiado para as teorizações e prática queer. (Pereira, 2008, p.505)

Os queers incomodam porque estão colocando em funcionamento corpos que não são homens nem mulheres. Colocam-nos questões como: lésbica significa mulher? Gay é homem? Há homens? Há mulheres?

Mais do que essa perguntas identificatórias, eu perguntaria: é um movimento em que se abandonam ou se reafirmam ontologizações? É possível universalizar políticas identitárias? Podemos ver corpos "homo" sem os comparar com corpos "hetero"? Podemos ver mulheres sem compará-las a homens e vice-versa? Podemos deixar de vez as produções binaristas? Respondem:

A multidão queer não tem a ver com um "terceiro sexo" ou um "mais além dos gêneros". Dedica-se á reapropriação das disciplinas dos saberes/poderes sobre os sexos, à rearticulação e a reconversão das tecnologias sexopolíticas concretas de produção dos corpos "normais" e "desviados". Á diferença das políticas "feministas" ou "homossexuais", a política da multidão queer não se baseia em uma identidade natural (homem/mulher), nem em uma definição baseada nas práticas (heterossexuais/homossexuais), mas em uma multiplicidade de corpos que se levantam contra os regimes que os constroem como "normais" 
ou "anormais": são as drag-king, as bolachas lobas, as mulheres barbudas, os trans-bichas sem pênis, os deficientes-ciborgues... O que está em jogo é como resistir ou como reconverter as formas de subjetivação sexopolíticas. (Preciado, 2004, p. 4).

\section{"Em fim"}

Busquei indicar que mesmo as intervenções médicas sobre os corpos são guiadas por políticas de gerenciamento diversas. $\mathrm{O}$ mesmo silicone tem feitos muito diversos em um "corpo mulher" ou em um "corpo homem".

Tenho certeza de que devemos agir sobre as políticas que continuam naturalizando-se em corpos, os considerando como pele ou invólucros de identidades e/ou performances, mas não só combatendo, ou como se diz "lutando" contra políticas binaristas. Também sem lutas, apenas pelo prazer da fluidez, fazer em nossas vidas momentos com ambiguidades, não porque são opostos, mas porque "sem elas não há mudanças" (Feyerabend, 1996, p.195).

A dança tem muito a nos ensinar quando os corpos não são vistos como invólucros, mas como o próprio acontecer. A dança e os corpos se acontecem. Não há danças sem corpos, não há corpos sem dança (movimento).

Ou seja, até que ponto a estratégia para "lutar contra" desigualdades está nas separações binárias, que encontram nos corpos a sua "evidência", separando homens e mulheres, gays e lésbicas, e intersex? Em outras palavras, precisamos ser sexuados, (performativamente ou não)? E se não mais procedermos binariamente como ficam as classificações biológicas, as teorias psi? Como ficam nossas pesquisas, metodologias? Estamos superando de uma vez por todas o Iluminismo com suas essências? Estamos abraçando o "pós-humanismo", o "transumano"? Ou uma vida "pré-individual" (Gilbert Simondon) que se define pelos agenciamentos que fazemos nessa grande maquinação mundial que produz individuações?

Antes que alguém indague "se o mundo é gay", aponto duas dificuldades que identifico nessa pergunta: (a) ontologização e universalização do mundo (o mundo é gay): o cajueiro é gay, o pirarucu, o cupuaçu, a rapadura, é gay; (b) atrelado a isso vem a noção de progresso: "o mundo gay é melhor do que o mundo hetero", ou seja, "há uma evolução". Só vejo uma pequena brecha (que não se identifica a priori com uma vagina ou um ânus ou entrada de um pênis). Uma brecha que se faz fluxo em todos os poros do mundo, que se for aberta com algum esforço, pode tornar-se uma saída para alguns. $\mathrm{O}$ mundo é queer. É estranho sempre, para sempre. Ou somos diferença (Deleuze, 1988) e que sejamos menos indiferentes. Não sabemos sobre o mundo além do que supomos. O mundo não é gay, não é trans, só é estranho e diferente. Não se nasce mulher, não se nasce homem, não se nasce gay, trans e também não se nasce com um corpo, mas nos tornamos humanos com uma biopolítica de gerenciamento de nossas vidas/corpos, que se incomoda com a impossibilidade de não podermos dar uma resposta final em relação a "definição sexual" e por isso, cria fármacos, conceitos, técnicas cirúrgicas, patologias e legislações.

Se nos produzimos como diferença ou como singulares, podemos ainda assim, caminhar por duas vias: (a) nos afirmamos como singulares, mas únicos, unos, com identidade, personalidade, caráter, alma, corpo, enfim um ser corporificado; (b) nos afirmamos como múltiplos, contraditórios, incoerentes, enfim, seres incorpóreos ou seres devir (Deleuze \& Guattari, 1995, pp.18-19). Haraway afirmar que "uma única visão produz ilusões piores do que uma visão dupla ou do que a visão de um monstro de múltiplas cabeças" (2009, p. 46). Assim, porque deveríamos postular uma nova identidade aos seres humanos seja ela única, simulacro ou múltipla? Cada uma destas posturas pode nos indicar tanto "dominações quanto possibilidades" (Haraway, 2009). Somos singulares como pontos que se formam em uma rede, mas que é também a junção de todas as linhas que nele fazem um nó. Assim, mais do que reivindicar uma ontologia ao ser humano, que abramos "nossos" chatôs para que nele e com ele se façam "nós". Aliás, esse pronome "nosso" também merece uma palavra. Está muito mais relacionado a um pertencimento e proveniência coletiva que também poderia ser expresso pelo seu feminino "nossa", que expressa admiração, tornando-se uma interjeição: "nossa!". Ou seja, os movimentos do viver humano, são mais "nossa!", do que "nossa" significando a posse de alguém.

Ainda uma palavra sobre os "nós". Nesse caso também não significando pronome, mas sendo entrelaçamento de fios (forças) que, ao mesmo tempo, podem significar tanto embaraço e dificuldade, quanto colmo de onde nascem novas formas. Nó então entendido como condição de possibilidade para que a vida, ávida, possa fluir unindo o que se pretende permanente e o devir. Assim os chamados seres humanos, merecem uma espantosa frase: "Nossa! Como nos fazemos em tantos nós!". Hibridizamo-nós em seres quase-máquinas, quase-humanos, quase-objetos e chamamos isso de vida. Porém os que claramente vivem isso, os que não podem ser definitivamente definidos (como se alguém pudesse!), são considerados abjetos, por serem escorregadios, por serem "nós" frouxos. Temos a ilusão que nos juntamos a idênticos, mas se escolhemos com o que/ quem queremos viver, o fazemos mais por afinidade do que por identidade (Haraway, 2009, p. 48). Que 
queremos dizer com isso? Se, como afirmamos acima, a opção seria a de não manter a ilusão de únicos, mas sim a ilusão de que somos, ao mesmo tempo, singulares e múltiplos como os "nós", nos entrelaçamos menos por sermos idênticos e mais por nos reconhecermos como afins e assim buscamos cúmplices que de algum modo possibilitam e favorecem a ilusão da vida.
Termino com uma poesia de Drummond em que aparece um diálogo do poeta com "seu corpo". Um corpo que se faz essência e, ao mesmo tempo, se faz devir na voz do autor. Um embate entre uma naturalização e essencialização do corpo que parece inerte e o corpo vida que flui.

AS CONTRADIÇÕES DO CORPO

\begin{tabular}{|c|c|c|}
\hline $\begin{array}{l}\text { Meu corpo não é meu corpo, } \\
\text { é ilusão de outro ser. } \\
\text { Sabe a arte de esconder-me } \\
\text { e é de tal modo sagaz } \\
\text { que a mim de mim ele oculta. }\end{array}$ & $\begin{array}{l}\text { Meu corpo ordena que eu saia } \\
\text { em busca do que não quero, } \\
\text { e me nega, ao se afirmar } \\
\text { como senhor do meu EU } \\
\text { convertido em cão servil }\end{array}$ & $\begin{array}{l}\text { Quero romper com meu corpo, } \\
\text { quero enfrentá-lo, acusá-lo, } \\
\text { por abolir minha essência, } \\
\text { mas ele sequer me escuta e vai pelo } \\
\text { rumo oposto. }\end{array}$ \\
\hline $\begin{array}{l}\text { Meu corpo, não meu agente, } \\
\text { meu envelope selado, } \\
\text { meu revólver de assustar, } \\
\text { tornou-se meu carcereiro, } \\
\text { me sabe mais que sei.... }\end{array}$ & $\begin{array}{l}\text { Se tento dele afastar-me, } \\
\text { por abstração ignorá-lo, } \\
\text { volta a mim com todo o peso de sua } \\
\text { carne poluída, } \\
\text { seu tédio, seu desconforto. }\end{array}$ & $\begin{array}{l}\text { Já premido por seu pulso } \\
\text { de inquebrantável rigor, } \\
\text { não sou mais quem dantes era: } \\
\text { com volúpia dirigida, } \\
\text { saio a bailar com meu corpo. }\end{array}$ \\
\hline
\end{tabular}

\section{Notas}

1 Disponível em http://www.beautyvulva.com.br/index. php?left=1\&main=front\&right=1 Acesso em 28 de março de 2009.

2 Dennis Avner entrou para o Guiness Book, livro dos recordes, como a pessoa no mundo que mais transformou seu corpo. $\mathrm{O}$ fez para ficar parecido com um gato.

3 Sobre a campanha ver: http://www.fcc.org.br/destaque/ incentivoAoPai/index.html. Acesso em 14 de setembro de 2009.

4 RHEG - A Rede de Homens pela Equidade de Gênero congrega um conjunto de organizações da sociedade civil e núcleos acadêmicos de gênero que atuam na promoção dos direitos humanos, com vistas a uma sociedade mais justa com equidade de direitos entre homens e mulheres. A Campanha do Laço Branco é a principal ação da Rede. Fazem parte da articulação: Instituto Promundo (RJ), Instituto Noos (RJ), Instituto PAPAI, Gema/UFPE (PE), ECOS (SP), Coletivo Feminista Sexualidade e Saúde (SP), Themis (RS) e Margens (SC). Ver: http://www.lacobranco.org.br/index.php.

\section{Referências}

Arilha, M., Ridenti, S., \& Medrado, B. (Orgs.). (1998). Homens e masculinidades: outras palavras. São Paulo: Ed. 34.

Bento, B. (2006). A reinvenção do corpo: sexualidade e gênero na experiência transexual. Rio de Janeiro: Garamond.

Butler, J. (2008). Cuerpos que importan: sobre los límites materiales y discursivos del "sexo". Buenos Aires: Paidós.

Butler, J. (2003). Problemas de gênero: feminismo e subversão da identidade (R. Aguiar, Trad.). Rio de Janeiro: Civilização Brasileira.

Castro, E. (2009). Vocabulário de Foucault. Belo Horizonte: Autêntica.
Cunha, A. G. (1986). Dicionário etimológico Nova Fronteira da língua portuguesa. Rio de Janeiro: Nova Fronteira.

Deleuze, G. (1988). Diferença e repetição. (L. Orlandi \& R. Machado, Trads.). Rio de Janeiro: Graal. (Trabalho original publicado em 1968)

Deleuze, G. (1992). Conversações (P. P. Pelbart, Trad.). São Paulo: Editora 34.

Deleuze, G. \& Guattari, F. (1995). Mil Platôs - Capitalismo e Esquizofrenia (Vol. 2). Rio de Janeiro: Ed. 34.

Feyerabend, P. K. (1996). Matando o tempo: uma autobiografia (R. Fiker, Trad.). São Paulo: Editora UNESP.

Fontes, J. B. (2006). O corpo e sua sombra [Prefácio à segunda edição]. In C. L. Soares (Org.), Corpo e história (3ª ed., s.p.). Campinas, SP: Autores Associados.

Foucault, M. (2008). Nascimento da biopolítica: curso dado no Collège de France (1078-1979) (E. Brandão, Trad.). São Paulo: Martins Fontes.

Haraway, D. (2009). Manifesto ciborgue: ciência, tecnologia e feminismo-socialista no final do século XX. In T. Tadeu (Org.), Antropologia do ciborgue - as vertigens do pós-humano (2 ed., pp. 33-118). Belo Horizonte: Autêntica.

Laqueur, T. (2001). Inventando o sexo: corpo e gênero dos gregos a Freud. Rio de Janeiro: Relume-Dumará.

Machado, P. S. (2005, janeiro/junho). O sexo dos anjos: um olhar sobre a anatomia e a produção do sexo (como se fosse) natural. Cadernos Pagu, 24, 249-281.

Medrado, B.(1998). Homens na arena do cuidado infantil: imagens veiculadas pela Mídia. In M. Arilha, S. Ridenti, \& B. Medrado (Orgs.), Homens e masculinidades: outras palavras (pp. 145-162). São Paulo: Ed. 34.

Monteiro, M. (1997). A perspectiva do gênero nos estudos de masculinidade: uma análise da revista Ele Ela em 1969. Acesso em 01 de maio, 2009, em http://www.artnet.com. br/ marko/artigo.html

Nunes, S. A. (2000). O corpo do diabo entre a cruz e a caldeirinha: um estudo sobre a mulher, o masoquismo e a feminilidade. Rio de Janeiro: Civilização Brasileira. 
Pedro, J. M. (2005). Traduzindo o debate: o uso da categoria gênero na pesquisa histórica. História, 24(01), 77-98.

Pereira, P. P. G. (2008). Corpo, sexo e subversão: reflexões sobre duas teóricas queer. Interface - Comunicação, Saúde, Educação, 12(26), 499-512.

Pinheiro, C. V. Q. (2006). Saberes e práticas médicas e a constituição da identidade pessoal. Physis Revista de Saúde Coletiva, 16(1), 45-58.

Preciado, B. (2002). Manifiesto contra-sexual: prácticas subversivas de identidad sexual. Madrid: Pensamiento Opera Prima.

Preciado, B. (2004, maio). Multitudes Queer - Notas para una política de los “anormales". Revue Multitudes, 12. Acesso em 20 de agosto, 2009, em http://multitudes.samizdat.net/ Multitudes-queer, 1465

Preciado, B. (2008). Testo Yonk. Madrid: Espasa.

Prins, B. \& Meijer, I. C. (2002, $1^{\circ}$ semestre). Como os corpos se tornam matéria: entrevista com Judith Butler (S. B. Funck, Trad.). Estudos Feministas, 10, 155-167.

Procuradoria Federal dos Direitos do Cidadão. (2009). Dicionário de Direitos humanos. Acesso em 01 de maio, 2009, em http://www.esmpu.gov.br/dicionario/tiki-index. php?page $=\mathrm{G} \% \mathrm{C} 3 \%$ AAnero

Rodrigues, C. (2005, janeiro/abril). Butler e a desconstrução do gênero. Estudos Feministas, 13(1), 179-199.

Sant'Anna, D. B. (1995). Políticas do corpo. São Paulo: Estação Liberdade.

Sant'Anna, D. B. (2001). Corpos de passagem: ensaios sobre a subjetividade contemporânea. São Paulo: Estação Liberdade.
Scott, J. W. (1995). Gênero: uma categoria útil de análise histórica. Educação e Realidade, 20(2), 71-99.

Silveira, F. A. \& Furlan, R. (2003). Corpo e alma em Foucault: postulados para uma metodologia da psicologia. Psicologia, 14(3), 171-194.

Soares, C. (Org.). (2006). Corpo e história ( $3^{\mathrm{a}}$ ed.). Campinas, SP: Autores Associados.

Ventura, M. \& Schramm, F. R (2009). Limites e possibilidades do exercício da autonomia nas práticas terapêuticas de modificação corporal e alteração da identidade sexual. Physis Revista de Saúde Coletiva, 19(1), 65-93.

Recebido em: 08/01/2010

Revisão em: 31/08/2010

Aceite final em: 23/09/2010

Ricardo Pimentel Méllo é Doutor em Psicologia Social (PUC-SP), Professor dos cursos de Graduação e PósGraduação em Psicologia da Universidade Federal do Ceará. Endereço: Rua Vilebaldo Aguiar, 1740/302. Cocó. Fortaleza/CE, Brasil. CEP 60.192-025. Email: ricardo_pm@uol.com.br

\section{Como citar:}

Méllo, R. P. (2012). Corpos, heteronormatividade e performances híbridas. Psicologia \& Sociedade, 24(1), 197-207. 